\title{
The Temporal Degradation of Illicit Contaminants in Latent Fingermarks Using Fourier Transform Infrared Spectroscopic Imaging
} Johnston A*

Defense Academy of the United Kingdom, Cranfield University, Shrivenham, Swindon, UK

"Corresponding author: Johnston A, Defense Academy of the United Kingdom, Cranfield University, Shrivenham, Swindon, UK, Tel: +441793785159; E-mail: a.johnston@cranfield.ac.uk

Received date: March 21, 2018; Accepted date: March 26, 2018; Published date: March 31, 2018

Copyright: ( 2018 Johnston A. This is an open-access article distributed under the terms of the Creative Commons Attribution License, which permits unrestricted use, distribution, and reproduction in any medium, provided the original author and source are credited.

\begin{abstract}
Fourier Transform Infrared (FTIR) spectroscopy has been shown to be a rapid, non-destructive analytical technique capable of detecting trace amounts of exogenous particulate in fresh latent fingermarks. Fingermarks identified at a crime scene however, are rarely fresh and are likely to have been deposited days or even weeks before forensic analysis, leaving them prone to decomposition.

In this study latent fingermarks were contaminated with trace amounts of the improvised explosive precursor's ammonium nitrate and sodium chlorate, and the addictive narcotic cocaine. The latent fingermarks where then aged in natural daylight conditions over a 30 day period and intermittently analysed using FTIR spectromicroscopy. Exogenous particulate was identified using spectroscopic imaging of each fingermark, and spectra obtained from the samples were compared to control spectra to confirm the identification of the contaminant. This study demonstrates that these contaminants are detectable within latent fingermarks up to at least 30 days after deposition, with only ammonium nitrate showing signs of decomposition, and that fingermark chemistry has a minimal effect on their molecular integrity. This information has broad implications for the law enforcement community as it suggests that the detection of exogenous particulate within latent fingermarks is possible long after a suspect has handled an illegal substance. This study also confirms the use of spectroscopic imaging to provide a chemical signature for these illicit compounds weeks after deposition, and an image of the fingermark ridge pattern that can then be used for identification purposes.
\end{abstract}

Keywords: Fingermarks; FTIR micro spectroscopy; Imaging; Detection; Explosives; Narcotics

\section{Introduction}

The ability to detect illicit substances such as explosive compounds/ precursors or narcotics in latent fingermarks is of obvious benefit to the forensic and law enforcement communities. This is of particular relevance to today's threat lists with the increased use of improvised explosive devices (IED's) by terrorist groups, often formulated from domestically available products, and the rising trend in cocaine consumption in Western Europe and the US.

Various analytical techniques have proven capable of detecting trace amounts of illicit materials, particularly in latent fingermarks, such as gas chromatography-mass spectroscopy (GC-MS), Matrix-assisted laser desorption/ionization-mass spectrometry (MALDI-MS), high performance liquid chromatography (HPLC), capillary electrophoresis, and ion mobility spectroscopy (IMS) [1-10]. These techniques, however, do require the destruction of the sample for analysis, leaving further investigation of the fingermark impossible. Whereas spectroscopic techniques such as Raman and Infrared spectroscopy are capable of detecting these illicit materials rapidly, with limited or no sample preparation and most importantly, are nondestructive with regards to the sample [8,11-16]. IR spectromicroscopy in particular has demonstrated the ability to identify exogenous particulate within latent fingermarks by generating identifiable spectra $[2,17]$, but is also capable of generating spectral images, or maps, that provide spatial information about a fingermark [17-24]. These spatial images can both identify the chemical signatures of foreign components within a fingermark, and also provide the spatial information of the unique ridge patterns that could be used to identify a suspect. The dynamic nature of fingermark chemistry postdeposition is a complex process, numerous studies have examined the chemical composition and aging of fingermarks, the oxidation mechanisms that take place, both short and long term $[25,26]$, and the resulting end products [26-36]. For example, it is well documented that the chemistry of latent fingermarks changes temporally in both adults and children [37-40] and this may potentially provide the basis for an aging tool to establish time since deposition.

The chemical components of latent fingermarks have been well documented using a variety of analytical techniques [41,42]. Previous studies have shown that there are changes in fingermark chemistry over time and under different conditions. Temporal decomposition [27,28,36,43-45], for example, appears to involve the shortening and degradation of unsaturated lipids including fatty acids, wax esters, triglycerides, and squalene (SQ) due to various oxidation processes $[25,26,32,33]$. In contrast, saturated lipids stay relatively stable over longer time periods ( $>60$ days) [26]. A change in unsaturated fatty acids has been observed over time decreasing significantly over a thirty-day period $[26,27]$. This is due to the unsaturated moiety degrading through both aerobic and anaerobic processes and increasing the proportion of unsaturated compounds [26]. Exposure to light also has a significant impact on fingermark composition. Studies have shown that exposure to light affects the breakdown mechanisms of various components within fingermark deposits differently and more rapidly than in dark conditions. Short chain fatty acids and 
squalene in particular were affected by exposure to light conditions $[27,28]$. Squalene (SQ) degradation is supported by the identification of various photo-oxidation mechanisms to produce intermediary products including peroxides, hydroperoxides and SQ epoxide and the fully oxidised forms being hexanedioic and pentanedioic acid [25]. These products are particularly prevalent when squalene is exposed to UV radiation, such as direct sunlight $[25,26,46]$.

The identification and chemical imaging of exogenous components within latent fingermarks, as well as the composition and aging of latent fingermarks has been, and continues to be, comprehensively studied. Investigations into the temporal degradation of foreign substances within fingermarks have largely been overlooked however. This is an important aspect of latent fingermark analysis as fingermarks found at crime scenes are rarely fresh, and could have been deposited days or weeks prior to investigation by law enforcement agencies. It is vital, therefore, to understand the effects of fingermark degradation chemistry on trace evidence over time. This study aims to address this gap in the literature by using FTIR spectromicroscopy to analyze the temporal degradation of three exogenous substances within latent fingermarks over a 30 day period. FT-IR spectromicroscopy is ideally suited to monitoring temporal changes in latent fingermarks as specific sample areas can be repeatedly analysed over the duration of the experiment [40,47].

Three substances were selected to contaminate the fingermarks; Ammonium nitrate (AN) and sodium chlorate (SC), both common pre-cursor components in IED's, and the addictive stimulant narcotic cocaine $(\mathrm{C})$. Fingermarks were contaminated with each one of these compounds and aged in natural light conditions over 30 days. The same sample area was analysed and a chemical map generated every 5 days for the duration of the experiment. Spectra of individual particles from each contaminant were also obtained at five day intervals to observe any changes in specific absorbance bands as the exogenous compounds interacted with the chemical makeup of the fingermarks.

\section{Experimental}

\section{Sample Preparation}

To prepare the fingermark samples the hands of the volunteer was cleaned with soapy water, rinsed and air dried for twenty minutes. The index finger of the right hand was drawn from the bridge of the nose to the temple five times to collect sufficient sebaceous secretions to simulate natural grooming behaviour. The volunteer's finger was then pressed into $500 \mathrm{mg}$ of the contaminant, any excess was brushed off with the other hand (gloved) until little or no powder was visible on the fingertip. The contaminated finger was then lightly pressed onto CaF2 Infrared (IR) microscope slides (10 mm x $10 \mathrm{~mm}$, Crystran Ltd). Fingermarks were laid down on consecutive days and deposited between 9am and 10am to avoid significant diurnal variations in composition of the latent fingermarks. For each fingermark the same index finger was used. An uncontaminated control fingermark was deposited on an identical CaF2 microscope slide, and five deposits were analysed from that sample. Control samples of $10 \mu \mathrm{g}$ of each contaminant were deposited on three separate $\mathrm{CaF} 2$ slides without the fingermark, five deposits were analysed from each slide. All sample fingermarks were obtained from a single male donor, 38 years old, to maintain a relative consistency between samples.
Contaminants: Ammonium nitrate $\geq 99 \%$ (Sigma Aldrich, UK), sodium chlorate $\geq 98 \%$ (Sigma Aldrich, UK), and cocaine free base CII $\geq 99 \%$ (Sigma Aldrich, UK), milled to a fine powder.

\section{Analysis of fingermarks}

The fingermarks were analysed using a PerkinElmer Spectrum ${ }^{\mathrm{TM}}$ Spotlight 200 FT-IR imaging system equipped with a liquid-nitrogen cooled MCT linear array detector. Data was analysed using Perkin Elmer software, Spectrum (v10.02.00); Variations in spectra were processed using peak area calculations. All spectra were baseline corrected and range normalized. Spectra from control samples and contaminated fingermarks were collected in transmission mode, over the 4000 to $750 \mathrm{~cm}^{-1}$ spectral range at $4 \mathrm{~cm}^{-1}$ spectral resolution and 10 $\mu \mathrm{m}$ spatial resolutions, after 32 scans, using a $100 \times 100 \mu \mathrm{m}$ aperture. All spectra were presented in units of absorbance $(\mathrm{A}=-\log \mathrm{T})$ as a function of wavenumber, the number of waves per centimeter. As with the control samples five deposits were selected for spectral analysis from each contaminated fingermark. Each fingermark and control sample was analysed every 5 days with both a visible image scan $(5000$ $\times 5000 \mu \mathrm{m})$, consisting of $169(13 \times 13)$ tiles, and a corresponding chemical map obtained from each sample. Before analysis began, contaminant particles were selected using the visual microscope capability and that area was sampled for the duration of the 30 day experiment. The same location was identified for each analysis by returning to the same area on the slide and identifying a characteristic group of particulate. The chemical maps allowed for individual spectra from each contaminant particle to be obtained and any changes in absorbance observed over the duration of the experiment. Changes in absorbance for the control samples and the contaminants within the fingermarks were calculated by selecting the 3 most dominant absorbance bands from each compound (Table 1), measuring their peak area after each scan, and averaging each sample. All samples were stored in natural light conditions at room temperature and humidity.

\begin{tabular}{|l|l|l|l|}
\hline & \multicolumn{3}{|l|}{ Absorbance bands selected for analysis $\left(\mathrm{cm}^{-1}\right)$} \\
\hline Sample & Band 1 & Band 2 & Band 3 \\
\hline Ammonium nitrate & 1628 & 1044 & 828 \\
\hline Sodium chlorate & 1887 & 1595 & 1415 \\
\hline Cocaine & 2946 & 1735 & 1449 \\
\hline Finger-mark & 2925 & 2858 & 1738 \\
\hline
\end{tabular}

Table 1: The three absorbance bands selected for analysis from the contaminants and the latent fingermarks over the duration of the experiment.

\section{Results and Discussions}

\section{Obtaining spectra and chemical maps}

Before the contaminated fingermarks were analysed control spectra were obtained from pure samples of the contaminants on day 0 and day 30 (Figure 1). 


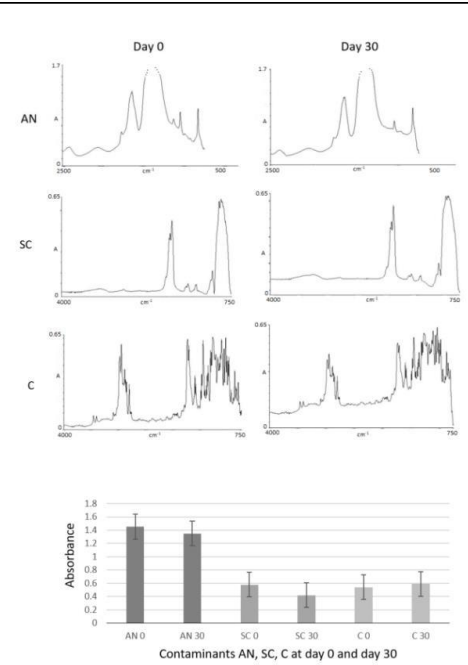

Figure 1: Averaged control spectra from five deposits of each of the contaminants; Ammonium nitrate (AN), sodium chlorate (SC), and cocaine $(\mathrm{C})$ on day 0 and day 30 .

Five deposits on each of the three slides containing $10 \mu \mathrm{g}$ of each contaminant were analysed. This was to identify any changes in absorbance, indicating degradation, that were unrelated to interactions with the fingermark chemistry. The spectral range of analysis for all samples was 4000 to $750 \mathrm{~cm}^{-1}$ with the exception of ammonium nitrate. The 'fingerprint region' of the ammonium nitrate spectrum $\left(2500 \mathrm{~cm}^{-1}-750 \mathrm{~cm}^{-1}\right)$ was selected for analysis for both the control and contaminated fingermark samples as this region provided the most accurate data on changes in absorbance over time. Control spectra and chemical maps of the uncontaminated latent fingermark were also obtained to identify the characteristic peaks, and any observable changes that occurred over the 30 day period (Figure 2).

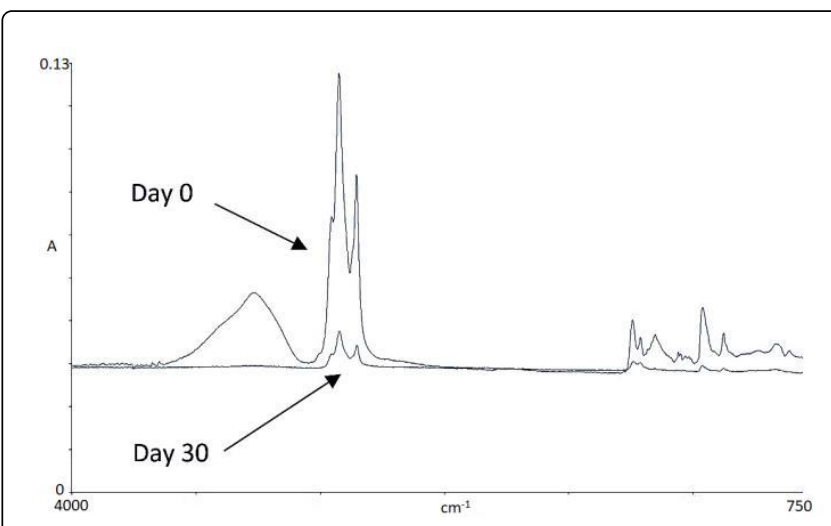

Figure 2: Averaged spectra of the uncontaminated latent fingermark at day 0 and day 30 .

There was no significant difference in selected absorbance bands between the control sample contaminants on day 0 and day 30 (Figure 1). This indicated that any changes in absorbance from the exogenous particulate within the fingermarks would be due to interactions with the fingermark chemistry.
The IR spectra in figure 2 shows a general reduction in peak area, and therefore quantity, across all bands of the uncontaminated control fingermark over the 30 day period, and notably the $\mathrm{OH}$ band at 3260 $\mathrm{cm}^{-1}$ showed a significant reduction, most likely due to water loss. Figure 3 shows that the absorbance of the anti-symmetric and symmetric C-H stretching modes of $\mathrm{CH} 2$ groups $\left(2920-2854 \mathrm{~cm}^{-1}\right)$ significantly decreased over 30 days, as would be expected. This band is a culmination of all the organic materials within a latent fingermark, and as mentioned above various oxidation mechanisms take place within a latent fingermark over time and materials such as triglycerides, wax esters, short chain fatty acids, and squalene decrease in quantity, especially in light conditions.

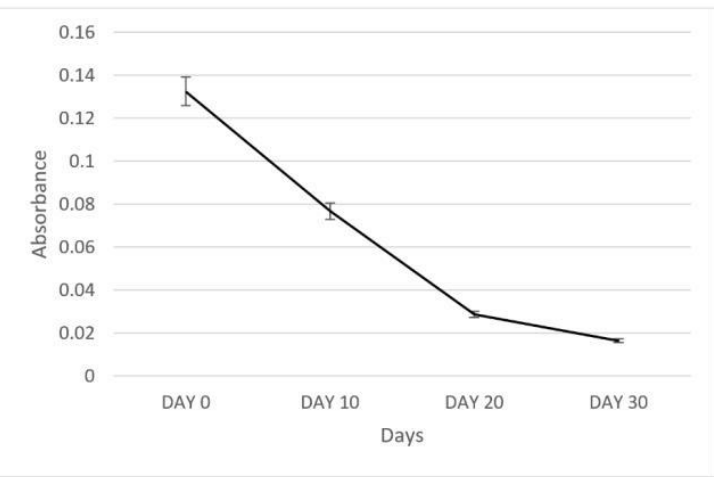

Figure 3: Change in absorbance of the $\mathrm{C}-\mathrm{H}$ stretching modes of $\mathrm{CH} 2$ groups of the control fingermark (uncontaminated) over 30 days.

Figure 4 shows the visible image and corresponding chemical map (chemimap) of the same area of a latent fingermark contaminated with ammonium nitrate. The ammonium nitrate particles observed in the visible image show strong absorbance in the chemimap.

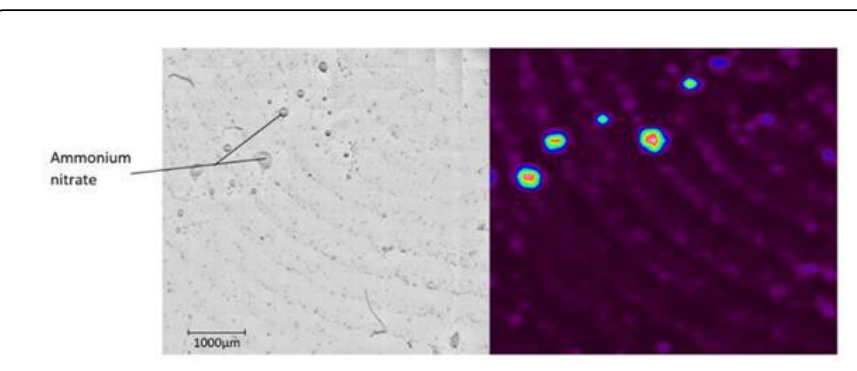

Figure 4: Visible image and corresponding chemimap of the fingermark contaminated with ammonium nitrate particles.

In Figure $5(\mathrm{a}-\mathrm{c})$ shows the individual spectra obtained from each of these particles, as well as a background spectrum of the fingermark figure 5 (d). The spectra confirm the identity of these particles as ammonium nitrate when compared to the control spectrum for ammonium nitrate figure 5 (e). This process was repeated for the fingermarks contaminated with sodium chlorate and cocaine. 
Citation: Johnston A (2018) The Temporal Degradation of Illicit Contaminants in Latent Fingermarks Using Fourier Transform Infrared Spectroscopic Imaging. J Forensic Res 9: 1000418. doi:10.4172/2157-7145.1000418

Page 4 of 6

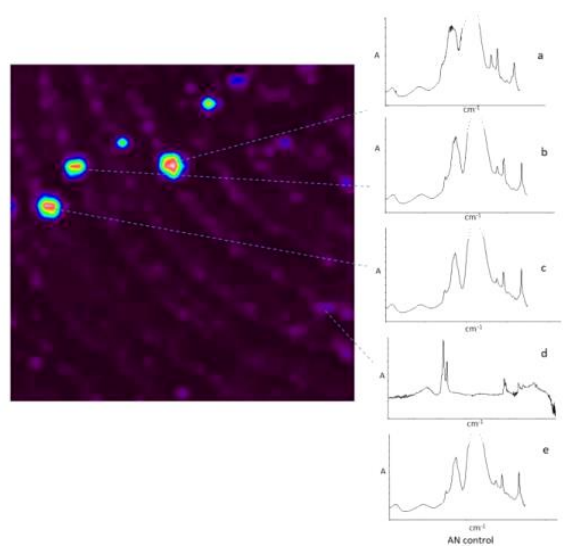

Figure 5: Chemimap and spectra of ammonium nitrate in a latent fingermark. (a), (b) and (c) show consistent spectra of ammonium nitrate particles present within the fingermark when compared to the control spectrum of ammonium nitrate (e), (d) shows a typical spectrum of a fingermark from the donor used in this study.

\section{Aged sample analysis using spectroscopic imaging}

The objective of this study was to investigate the degradation effects of fingermark chemistry on different contaminants over a 30 day period using FT-IR spectroscopic imaging. The above results demonstrate that there is no significant degradation of the contaminant control samples over time (Figure 1), and that it is possible to reliably detect exogenous particulate within latent fingermarks using chemical mapping (Figures 4 and 5).

Figure 6 shows two examples of spectroscopic images of latent fingermarks contaminated with ammonium nitrate figure 6 (A) and cocaine figure 6 (B) on day 0 and day 30 .

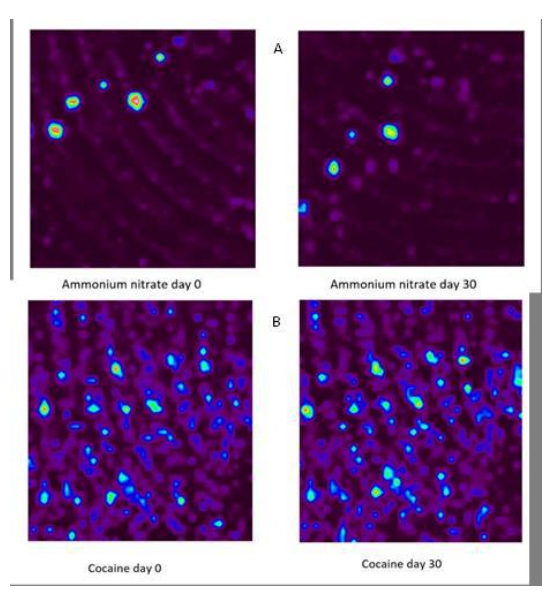

Figure 6: Chemimap comparison of ammonium nitrate and cocaine on day 0 and day 30 .

In Figure $6(\mathrm{~A})$ the chemimaps show an observable difference in the average absorbance, and therefore quantity of material, of ammonium nitrate from day 0 to day 30 , but there is no obvious difference between the chemimaps of fingermarks contaminated with cocaine. This reduction in average absorbance between day 0 and day 30 for ammonium nitrate as shown in figure 6 (A) was confirmed by the specific peak area calculations from the spectral data (Figure 7), but these changes were not seen in the spectra of the sodium chlorate or cocaine samples N.B. The saturated nitrate ion band at $1410-1340 \mathrm{~cm}^{-1}$ is a natural consequence of absorption in the larger ammonium nitrate particulates, typical of that within fingermark contamination. This band was not used in any calculations for this study.

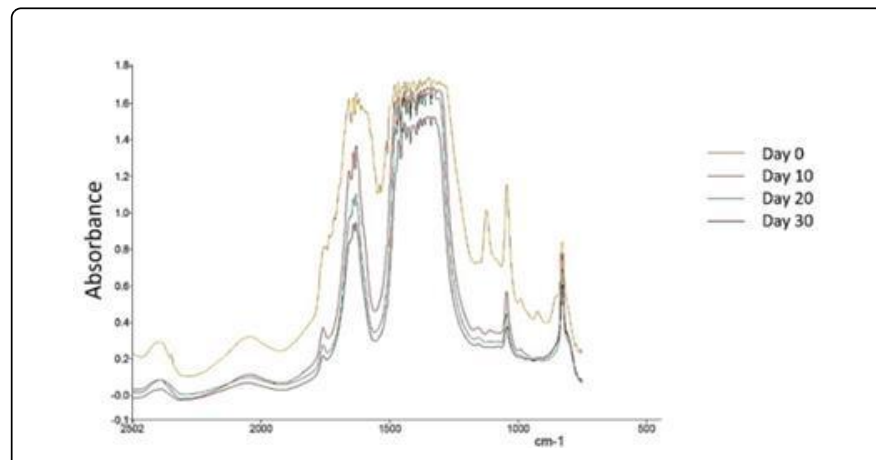

Figure 7: Change in absorbance of ammonium nitrate over 30 days, focusing on absorbance bands at $1628,1044,828 \mathrm{~cm}^{-1}$.

To establish any quantifiable change in absorbance of the three contaminants over the 30 day period spectral data was analysed using peak area analysis, and Spearman's Rho Correlation was used to identify any significant correlation between time and average absorbance of the three contaminants. No significant correlation was observed for sodium chlorate $(\mathrm{p}=0.2)$ or cocaine $(\mathrm{p}=0.05)$, but there was a significant reduction in absorbance for ammonium nitrate $(p=0.00)$ over the 30 day period. Figure 8 plots the average absorbance for each of the three contaminants over the 30 day period. As confirmed by the Spearman's Rho correlation only ammonium nitrate showed a significant decrease in quantity, although this reduction occurred almost entirely within the first 10 days, and ammonium nitrate particulates were still detectable after 30 days (Figure $6 \mathrm{~A}$ and 7).

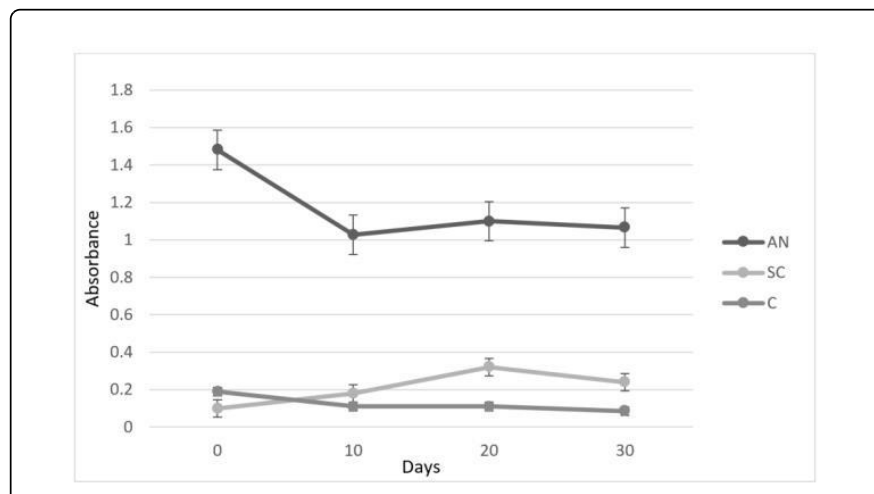

Figure 8: Changes in specific peak absorbance over a 30 day period for ammonium nitrate, sodium chlorate and cocaine.

Ammonium nitrate showed a $31 \%$ decrease in absorbance in the first ten days and then only a $4 \%$ decrease over the following twenty days. It is likely that this initial reduction in absorbance of Ammonium nitrate is due to ionic interactions with both water molecules and 
unsaturated lipid components within the fingermark. It is known that these unsaturated lipids, such as squalene and unsaturated fatty acids, decompose within the first few days' post-deposition [27,28,36,43]. Polar water molecules will break the ionic bonds within ammonium nitrate to form ammonium and nitrate ions, these ions would then be available to interact with the unsaturated lipids. This interaction between the inorganic ions and unsaturated lipids would also be assisted by the photo-oxidation mechanisms that are known to take place in light conditions $[27,28]$. The lack of change in absorbance after ten days is likely to be in part due to the evaporation of water from the fingermark, and due to the near complete decomposition of these unsaturated lipids.

Ammonium nitrate and sodium chlorate are ionic compounds so it might be expected that they would both show some degradation over time in the aqueous and dynamic environment of a latent fingermark. Yet it was only Ammonium nitrate that degraded over the 30 day period, SC remaining unchanged. This is likely due to the difference in lattice enthalpy of the two compounds. Ammonium nitrate has a significantly lower lattice enthalpy than SC, so is more likely to form ions in solution in the ambient conditions of a latent fingermark. Cocaine is a covalently bonded alkaloid ester, so the lack of change in absorbance over time in this study is consistent with its intramolecular stability.

\section{Conclusion}

This study demonstrates that traces amounts of ammonium nitrate, sodium chlorate, and cocaine, are still detectable in latent fingermarks up to at least 30 days since deposition in ambient conditions. It also reiterates the advantages of using FTIR spectromicroscopy to identify trace amounts of contaminant within latent fingermarks, and the ability to analyse any chemical changes in that contaminant over time without destroying the sample. All three contaminants were detectable after 30 days, only ammonium nitrate showed any significant reduction in quantity over the test period, primarily in the first 10 days. This study used one donor for the fingermarks, which, given the reported variability between individuals, could be considered limiting with regard to chemical variation. It was felt however, that for this study, this consistency was an advantage in assessing changes in contaminant composition over time. Further research should look into the effect of various donors on the chemical integrity of these contaminants, which may in addition provide more information on the chemical variability between individuals.

The variety of illicit contaminants, from either explosive/explosive precursors or narcotics that could potentially be found in latent fingermarks is immensely broad. Although only three contaminants were selected for this study the data does suggest that any contaminant degradation that does occur is likely to arise within ten-days of fingermark deposition. This is when the naturally occurring oxidation mechanisms within a latent fingermark are most active and therefore intermolecular interactions with other species are more likely. It is also when the water content of a fingermark is at its highest enabling the more polar compounds to form a solution. It is worth noting that the fingermarks used for this study were sebaceous-loaded to represent natural grooming behaviour. This loading however, can artificially enrich fingermarks with lipid components, and may affect degradation rates of certain contaminants given there are more lipid materials to interact with. Although even with sebaceous-loaded fingermarks the contaminants in this study were still detectable for the duration of the experiment.
In this work FTIR spectromicroscopy has demonstrated the ability to not only chemically identify trace amounts of illicit compounds within latent fingermarks weeks after deposition, but also to simultaneously provide a recognizable ridge pattern that can be used for identification purposes without destroying the sample. This data has broad implications for the law enforcement community as the ability to detect illicit compounds in latent fingermarks a considerable time after deposition is potentially of great value to a criminal investigation, for example when tracing the movements of a terrorist or terrorist group synthesizing improvised explosive compounds. Further work is needed on a broader range of illicit substances to identify any compounds that are particularly susceptible to degradation within the chemical environment of a latent fingermark, and how varying environmental conditions could affect that rate of decomposition.

\section{References}

1. Banas A, Banas K, Breese MB, Loke J, Heng Teo B, et al. (2012) Detection of microscopic particles present as contaminants in latent fingerprints by means of synchrotron radiation-based fourier transform infra-red microimaging. Analyst 137: 3459-3465.

2. Mou Y, Rabalais JW (2009) Detection and identification of explosive particles in fingerprints using attenuated total reflection-fourier transform infrared spectromicroscopy. J Forensic Sci 54: 846-850.

3. Moore DS (2004) Instrumentation for trace detection of high explosives. Rev Sci Instrum 75: 2499-2512.

4. Nambayah M, Quickenden TI (2007) A quantitative assessment of chemical techniques for detecting traces of explosives at counter-terrorist portals. Talanta 63: 461-467.

5. Singh S (2007) Sensors-an effective approach for the detection of explosives. J Hazard Mater 144: 15-28.

6. Lai H, Leung A, Magee M, Almirall JR (2010) Identification of volatile chemical signatures from plastic explosives by SPME-GC/MS and detection by ion mobility spectrometry. Anal Bioanal Chem 396: 2997-3007.

7. Rowell F, Seviour J, Lim AY, Elumbaring-Salazar CG, Loke J, et al. (2012) Detection of nitro-organic and peroxide explosives in latent fingermarks by DART- and SALDI-TOF-mass spectrometry. Forensic Sci Int 221: 84-91.

8. Grant A, Wilkinson TJ, Holman DR, Martin MC (2005) Identification of recently handled materials by analysis of latent human fingerprints using infrared spectromicroscopy. Appl Spectrosc 59: 1182-1187.

9. Francese S, Bradshaw R, Denison N (2017) An update on MALDI mass spectrometry based technology for the analysis of fingermarks-stepping into operational deployment. Analyst 142: 2518-2546.

10. Groeneveld G, de Puit M, Bleay S, Bradshaw R, Francese S (2015) Detection and mapping of illicit drugs and their metabolites in fingermarks by MALDI MS and compatibility with forensic techniques. Sci Rep 5: 11716.

11. Williams DK, Schwartz RL, Bartick EG (2004) Analysis of latent fingerprint deposits by infrared microspectroscopy. Appl Spectrosc 58: 313-316.

12. Day JS, Edwards HG, Dobrowski SA, Voice AM (2004) The detection of drugs of abuse in fingerprints using Raman spectroscopy II: Cyanoacrylate-fumed fingerprints. Spectrochim Acta A Mol Biomol Spectrosc 60: 1725-1730.

13. Day JS, Edwards HG, Dobrowski SA, Voice AM, (2004) The detection of drugs of abuse in fingerprints using Raman spectroscopy I: latent fingerprints. Spectrochim Acta A Mol Biomol Spectrosc 60: 563-568.

14. Cheng C, Kirkbride T, Batchelder D, Lacey R, Sheldon T (1995) In-situ detection and identification of trace explosives by raman microscopy BT. J Forensic Sci 40: 31-37. 
Citation: Johnston A (2018) The Temporal Degradation of Illicit Contaminants in Latent Fingermarks Using Fourier Transform Infrared Spectroscopic Imaging. J Forensic Res 9: 1000418. doi:10.4172/2157-7145.1000418

Page 6 of 6

15. West MJ, Went MJ (2008) The spectroscopic detection of exogenous material in fingerprints after development with powders and recovery with adhesive lifters. Forensic Sci Int 174: 1-5.

16. Tripathi A, Emmons ED, Wilcox PG, Guicheteau JA, Emge DK, et al. (2011) Semi-automated detection of trace explosives in fingerprints on strongly interfering surfaces with raman chemical imaging. Appl Spectrosc 65: 611-619.

17. Ricci C, Phiriyavityopas P, Curum N, Chan KL, Jickells S, et al. (2007) Chemical imaging of latent fingerprint residues. Appl Spectrosc 61: 514-522.

18. Ng PH, Walker S, Tahtouh M, Reedy B (2009) Detection of illicit substances in fingerprints by infrared spectral imaging. Anal Bioana. Chem 394: 2039-2048.

19. Crane NJ, Bartick EG, Perlman RS, Huffman S (2007) Infrared spectroscopic imaging for non-invasive detection of latent fingerprints. J Forensic Sci 52: 48-53.

20. Tahtouh M, Despland P, Shimmon R, Kalman JR, Reedy BJ (2007) The application of infrared chemical imaging to the detection and enhancement of latent fingerprints: Method optimization and further findings. J Forensic Sci 52: 1089-1096.

21. Payne G, Wallace C, Reedy B, Lennard C, Schuler R, et al. (2005) Visible and near-infrared chemical imaging methods for the analysis of selected forensic samples. Talanta 67: 334-344.

22. Bartick E, Schwartz R, Bhargava R, Schaeberle M, Fernandez D, et al (2002) Spectrochemical analysis and hyperspectral imaging of latent fingerprints In: 16th meeting of the international association of forensic sciences. International Assoc Forens Sci 61-64.

23. Mercado AG, Janni JA, Gilbert B (1995) Image analysis of explosives fingerprint contamination using a Raman imaging spectrometer. Proc SPIE 2511: 142-152.

24. Ricci C, Bleay S, Kazarian SG (2007) Spectroscopic imaging of latent fingermarks collected with the aid of a gelatin tape. Anal Chem 79: 5771-5776.

25. Mountfort KA, Bronstein H, Archer N, Jickells SM (2007) Identification of oxidation products of squalene in solution and in latent fingerprints by ESI-MS and LC/APCI-MS. Anal Chem 79: 2650-2657.

26. Mong GM, Petersen CE, Clauss TRW (1999) Advanced fingerprint analysis project fingerprint constituents. Pacific north-west national laboratory: U.S Department of Energy.

27. Archer NE, Charles Y, Elliott JA, Jickells S (2005) Changes in the lipid composition of latent fingerprint residue with time after deposition on a surface. Forensic Sci Int 154: 224-239.

28. Croxton RS, Baron MG, Butler D, Kent T, Sears VG (2010) Variation in amino acid and lipid composition of latent fingerprints. Forensic Sci Int 199: 93-102.

29. Ramotowski R (2001) Composition of latent print residues in: Advanced in fingerprint technology, 2nd edn, CRC Press, London, UK.

30. Srivastava A, Prasad R, Triglycerides-based diesel fuels. Renew Sust Energy Rev 4: 111-113.
31. Dent BB, Forbes SL, Stuart BH (2004) Review of human decomposition processes in soil. Environ Geol 45: 576-585.

32. Wolstenholme R, Bradshaw R, Clench MR, Francese S (2009) Study of latent fingermarks by matrix-assisted laser desorption/ionisation mass spectrometry imaging of endogenous lipids. Rapid Commun Mass Spectrom 23: 3031-3039.

33. Weyermann C, Roux C, Champod C (2011) Initial results on the composition of fingerprints and its evolution as a function of time by GC/MS analysis. J Forensic Sci 56: 102-108.

34. Iuliano L (2011) Pathways of cholesterol oxidation via non-enzymatic mechanisms. Chem Phys Lipids 164: 457-468.

35. Kim SK, Nawar WW (1991) Oxidative interactions of cholesterol with triacylglycerols. J Am Oil Chem Soc 68: 931-934.

36. Girod A, Ramotowski R, Weyermann C (2012) Composition of fingermark residue: A qualitative and quantitative review. Forensic Sci Int 223: 10-24.

37. Buchanan MV, Asano KG, Bohanon A (1996) Chemical characterization of fingerprints from adults and children. Int Soc Opt Eng 2941: 89-95.

38. Williams DK, Brown CJ, Bruker J (2011) Characterization of children's latent fingerprint residues by infrared microspectroscopy: Forensic implications. Forensic Sci Int 206: 161-165.

39. Noble D (1995) Vanished into thin air. The search for children's fingerprints. Anal Chem 67: 435A-438A.

40. Antoine KM, Mortazavi S, Miller AD, Miller LM (2010) Chemical differences are observed in children's versus adults' latent fingerprints as a function of time. J Forensic Sci 55: 513-518.

41. Bailey MJ, Bright NJ, Croxton RS, Francese S, Ferguson LS, et al. (2012) Chemical characterization of latent fingerprints by matrix-assisted laser desorption ionization, time-of-flight secondary ion mass spectrometry, mega electron volt secondary mass spectrometry, gas chromatography/ mass spectrometry, X-ray photoelectron spectroscopy, and attenuated total reflection Fourier transform infrared spectroscopic imaging: an intercomparison. Anal Chem 84: 8514-8523.

42. Cadd S, Islam M, Manson P, Bleay S (2015) Fingerprint composition and aging: A literature review. Sci Justice 55: 219-238.

43. Girod A, Xiao L, Reedy B, Roux C, Weyermann C (2015) Fingermark initial composition and aging using fourier transform infrared microscopy ( $\mu$-FTIR). Forensic Sci Int 254: 185-196.

44. Cuthbertson F, Morris JR (1972) The Chemistry of fingerprints, memorandum332.

45. Fritz P, van Bronswjik W, Lepkova K (2013) Infrared microscopy studies of the chemical composition of latent fingermark residues. Microchem J 111: 40-46.

46. Picardo M, Zompetta C, De Luca C, Amantea A, Faggioni A, et al. (1991) Squalene peroxides may contribute to ultraviolet light-induced immunological effects. Photodermatol Photoimmunol Photomed 8: 105-110.

47. Johnston A, Rogers K (2017) The effect of moderate temperatures on latent fingerprint chemistry. Appl Spectrosc 71: 2102-2110. 